\title{
PENGUNGKAPAN TANGGUNG JAWAB SOSIAL PERUSAHAAN MANUFAKTUR: STUDI EMPIRIS TATA KELOLA
}

\author{
DYLAN BILLY JAPOETRA \\ YULIUS KURNIA SUSANTO \\ Sekolah Tinggi Ilmu Ekonomi Trisakti, Jl. Kyai Tapa No. 20 Jakarta, Indonesia \\ dylanbilly21@gmail.com, yulius@tsm.ac.id
}

\begin{abstract}
This study is aim to examine the effect of managerial ownership, public ownership, board independence, audit committee, and board size on corporate sosial responsibility disclosure. This research is developed based on the previous research by Khan et al. (2013). The sample uses in this research is based on the data 180 manufacturing companies listed in Indonesia Stock Exchange during years 2014-2016. Sample are selected using purposive sampling method. Data analysis was using multiple regression analysis. The result showed that the public ownership, and board size have positive influence on corporate sosial responsibility disclosure. While managerial ownership, board independence, audit committee have no effect on the disclosure of corporate social responsibility.
\end{abstract}

Keywords: Corporate sosial responsibility disclosure, managerial ownership, public ownership, board independence, audit committee, board size

Abstrak: Penelitian bertujuan untuk menguji pengaruh kepemilikan managerial, kepemilikan publik, dewan direksi independen, komite audit, ukuran dewan, terhadap pengungkapan tanggung jawab sosial perusahaan. Penelitian ini merupakan pengembangan dari penelitian yang dilakukan oleh Khan et al. (2013). Sampel yang digunakan adalah 180 data perusahaan manufaktur yang terdapat di Bursa Efek Indonesia selama tahun 2014-2016. Metode pengambilan sampel yang digunakan adalah metode purposive sampling. Analisis data menggunakan analisis regresi berganda. Hasil penelitian ini menunjukan bahwa kepemilikan publik, dan board size memiliki pengaruh positif terhadap pengungkapan tanggung jawab sosial perusahaan. Sedangkan kepemilikan menegerial, dewan direksi independen, dan komite audit tidak memiliki pengaruh terhadap pengungkapan tanggung jawab sosial perusahaan.

Kata kunci: Pengungkapan tanggung jawab social perusahaan, kepemilikan menegerial, kepemilikan publik, dewan direksi independen, komite audit, ukuran dewan

\section{PENDAHULAN}

Corporate Social Responsibility (CSR) telah menjadi topik penting dalam penulisan akademik dan bidang bisnis. Banyak organisasi atau institusi di seluruh dunia sangat menekankan bahwa perusahaan harus mempertimbangkan dampak ekonomi, sosial dan lingkungan dari kegiatan mereka.
Pengungkapan tanggung jawab sosial perusahaan merupakan proses penyediaan informasi pelaporan tata kelola perusahaan dan pelaporan tanggung jawab sosial perusahaan (CSR) secara terpisah, namun perhatian yang relatif sedikit telah dilakukan dalam membuat hubungan antara keduanya. Karena pengungkapan CSR dipengaruhi oleh pilihan, motif dan nilai dari mereka yang terlibat dalam 
perumusan dan pengambilan keputusan dalam organisasi, pertimbangan mekanisme tata kelola perusahaan, khususnya struktur kepemilikan dan komposisi dewan dapat menjadi faktor penentu (Haniffa dan Cooke 2005). Pentingnya CSR pada perusahaan mampu menjadi faktor penentu keberlangsungan perusahaan. Perusahaan yang memiliki kinerja lingkungan yang baik dan melakukan pengungkapan yang tinggi memposisikan mereka sebagai perusahaan yang memiliki aktivitas yang berguna dan kualitas pengungkapan ini juga didorong legitimasi terhadap masyarakat.

Jo dan Harjoto (2011) telah banyak menemukan pilihan CSR dan kinerja yang berhubungan positif dengan internal dan mekanisme tata kelola perusahaan eksternal, seperti dewan komisaris independensi, kepemimpinan dewan dan kepemilikan institusional. Melihat kondisi tersebut, perusahaan-perusahaan di Indonesia mulai menyadari dan mengambil langkah untuk memperbaiki hubungan mereka dengan lingkungan sosial. Praktik pengungkapan CSR ini sendiri telah diterapkan oleh cukup banyak perusahaan publik di Indonesia, salah satunya melalui laporan tahunan perusahaan. Secara sederhana, perusahaan mengungkapkan bentuk tanggung jawab sosial dalam laporan tahunan. Walaupun informasi yang dicantumkan tidak dijelaskan secara mendetail, namun itikad perusahaan perlu diapresiasi karena perusahaan telah telah memiliki kesadaran akan pentingnya pengungkapan informasi terkait CSR. Bentuk pengungkapan dapat disesuaikan dengan kebutuhan dan kompleksitas organisasi.

Corporate Social Responsibility (CSR) diartikan sebagai komitmen usaha untuk bertindak etis, beroperasi secara legal dan berkontribusi untuk peningkatan ekonomi bersamaan dengan peningkatan kualitas hidup dari karyawan dan keluarganya, komunitas lokal dan masyarakat secara lebih luas. Tanggung jawab sosial perusahaan (CSR) dapat diartikan sebagai bentuk kewajiban organisasi bisnis untuk mengambil bagian dalam kegiatan yang bertujuan melindungi dan meningkatkan kesejahteraan masyarakat secara keseluruhan. Disiplin ilmu akuntansi mengakomodasi perkembangan isu tanggung jawab sosial perusahaan (CSR) dengan mengembangkan wacana Social Responsibility Accounting (SRA) atau akuntansi pertanggungjawaban sosial (Belkaoui 2006).

Penelitian ini merupakan pengembangan dari penelitian yang dilakukan oleh Khan et al. (2013). Tujuan penelitian ini adalah untuk memperoleh bukti empiris mengenai kepemilikan menegerial, kepemilikan publik, dewan direksi independen, komite audit, ukuran dewan terhadap corporate social responsibility disclosure.

\section{Kepemilikan Menegerial}

Pada perusahaan tertentu, untuk memotivasi kinerja manajer, perusahaan mulai menerapkan kebijakan kepemilikan manajerial. Kebijakan ini dimaksudkan untuk memberikan kesempatan bagi para manajer untuk terlibat dalam kepemilikan saham perusahaan, sehingga dalam terlibatnya ini kedudukan para manajer menjadi sama dengan kedudukan para pemegang saham. Manajer diperlakukan bukan semata sebagai pihak eksternal yang digaji untuk kepentingan perusahaan tetapi diperlakukan sebagai pemilik perusahaan. Dengan demikian, dengan diadakannya keterlibatan manajer diharapkan dapat meningkatkan kinerjanya secara efektif Dewanta (2011).

Menurut Jensen dan Meckling (1976) ketika kepemilikan saham oleh manajemen rendah maka ada kecenderungan akan terjadinya perilaku opportunistik manajer yang meningkat akan juga. Kepemilikan manajemen tidak hanya berpengaruh terhadap pengambilan keputusan, tetapi juga berhubungan dengan saham. Maka dengan adanya kepemilikan manajemen terhadap saham perusahaan dapat dipandang baik dalam menyelaraskan potensi perbedaan kepentingan antara manajemen dan pemegang saham (Susanto 2019). Berdasarkan 
uraian tersebut, maka dirumuskan hipotesis sebagai berikut:

$\mathrm{H}_{1}$ : Terdapat pengaruh kepemilikan menegerial terhadap coporate social responsibility disclosure.

\section{Kepemilikan Publik}

Perusahaan yang dimiliki oleh publik diharapkan memiliki lebih banyak tekanan untuk mengungkapkan informasi tambahan karena masalah visibilitas dan akuntabilitas yang diakibatkan oleh sejumlah besar pemangku kepentingan. Hal ini mungkin memerlukan keterlibatan tambahan dalam kegiatan sosial atau komunitas dan karenanya pengungkapan kegiatan ini. Hal ini mungkin memerlukan keterlibatan tambahan dalam kegiatan sosial atau komunitas dan karenanya pengungkapan kegiatan ini. Dengan demikian, diharapkan konsentrasi pemilikan publik dikaitkan secara positif dengan tingkat aktivitas sosial (Khan et al. 2013).

Untuk mendorong kemauan publik untuk berinvestasi pada sebuah perusahaan, perusahaan harus menampilkan keunggulan yang dimiliki terutama aktivitas sosialnya. Hasil yang telah diperoleh yakni variabel kepemilikan publik memiliki pengaruh positif signifikan (Susanto \& Joshua 2018, Sriayu \& Mimba 2013). Berdasarkan uraian tersebut, maka dirumuskan hipotesis sebagai berikut:

$\mathrm{H}_{2}$ : Terdapat pengaruh kepemilikan publik terhadap coporate social responsibility disclosure.

\section{Dewan Direksi Independen}

Dalam konteks corporate governance, direksi independen diharapkan dapat melakukan peran pemantauan untuk memastikan agar kepentingan pemegang saham dipertimbangkan saat sampai pada keputusan dewan direksi. Namun, hubungan antara direksi independen dan tingkat pengungkapan CSR tidak jelas. Independensi dewan merupakan ciri penting lainnya dalam tata kelola perusahaan. Advokat teori agensi mengusulkan agar direksi independen di dewan direksi dapat menghindari masalah keagenan dan memperkaya kualitas pemetaan dewan hasil (Jensen dan Meckling 1976).

Direksi independen merupakan ciri penting lainnya dalam tata kelola perusahaan. Advokat teori agensi mengusulkan agar direksi independen di dewan direksi dapat menghindari masalah keagenan dan dewan hasil. Susanto \& Joshua (2018), Barako \& Brown (2008) menyatakan adanya hubungan positif antara direksi independen dan pengungkapan CSR. Berdasarkan uraian tersebut, maka dirumuskan hipotesis sebagai berikut:

$\mathrm{H}_{3}$ : Terdapat pengaruh dewan direksi independen terhadap coporate social responsibility disclosure.

\section{Komite Audit}

Komite audit mengomentari dan menyetujui pilihan kebijakan akuntansi, oleh karena itu, diharapkan dapat mempengaruhi pendekatan perusahaan terhadap pelaporan dan pengungkapan keuangan. Penelitian sebelumnya telah membuktikan bahwa komite audit memainkan peran efektif dalam meningkatkan standar tata kelola perusahaan. Komposisi komite audit sangat terkait dengan pelaporan keuangan sebagai penghubung adanya audit dan tingkat pelaporan yang lebih andal. Keberadaan komite audit terkait dengan tingkat keterbukaan sukarela, sehingga keberadaannya dalam menghasilkan pelaporan berkualitas tinggi (Turley dan Zaman 2004).

$$
\text { Penelitian sebelumnya telah }
$$

membuktikan bahwa komite audit memainkan peran efektif dalam meningkatkan standar tata kelola perusahaan, komposisi komite audit sangat terkait dengan pelaporan keuangan. Keberadaan komite audit secara signifikan dan positif terkait dengan pengungkapan tanggung jawab sosial perusahaan (Susanto \& Joshua 2018). Berdasarkan uraian tersebut, maka dirumuskan hipotesis sebagai berikut:

$\mathrm{H}_{4}$ : Terdapat pengaruh komite audit terhadap coporate social responsibility disclosure. 


\section{Ukuran Dewan}

Ukuran dewan adalah jumlah personel dewan direksi dan komisaris dalam suatu perusahaan. Lipton dan Lorch (1992) menyatakan terdapat beberapa kekurangan dalam besarnya ukuran dewan direksi. Ukuran dewan direksi yang besar akan berakibat pada kurangnya diskusi yang berarti, sebab mengekspresikan pendapat dalam kelompok besar umumnya memakan waktu, sulit dan mengakibatkan kurangnya kekompakan pada dewan direksi.

Perusahaan yang memiliki karakteristik dewan yang efektif, dewan komisaris independen, kepemilikan manajerial, dianggap secara positif sebagai warga perusahaan yang lebih baik dan lebih bertanggung jawab secara sosial dan lingkungan. Hal ini mengindikasikan bahwa harus ada hubungan positif yang kuat antara karakteristik dewan dan CSRD perusahaan (Susanto 2019, Hannifah \& Cooke
2005). Berdasarkan uraian tersebut, maka dirumuskan hipotesis sebagai berikut:

$\mathrm{H}_{5}$ : Terdapat pengaruh ukuran dewan terhadap coporate social responsibility disclosure.

\section{METODE PENELITIAN}

Pengungkapan tanggung jawab sosial perusahaan dianalisis dengan melakukan checklist berdasarkan indeks Sembiring (2005). Apabila item pengungkapan tersebut terdapat dalam laporan tahunan perusahaan maka diberikan nilai 1 dan jika item tidak ada dalam laporan tahunan perusahaan maka akan diberikan nilai 0 . Hasilnya akan dijumlahkan dan kemudian akan dibagi dengan nilai maksimum indeks pengungkapan tanggung jawab sosial yaitu 78 . Total data yang digunakan dalam penelitian adalah 180 data, dimana prosedur pemilihan sampel dapat dilihat pada tabel dibawah ini:

\section{Tabel 1 Prosedur Pemilihan Sampel}

\begin{tabular}{|c|c|c|}
\hline Kriteria Sampel & $\begin{array}{c}\text { Jumlah } \\
\text { Perusahaan }\end{array}$ & $\begin{array}{c}\text { Jumlah } \\
\text { Data }\end{array}$ \\
\hline $\begin{array}{l}\text { Perusahaan manufaktur yang terdaftar di Bursa Efek } \\
\text { Indonesia secara konsisten selama tahun } 2014 \text { sampai } \\
\text { dengan } 2016\end{array}$ & 149 & 447 \\
\hline $\begin{array}{l}\text { Perusahaan manufaktur yang tidak menyampaikan } \\
\text { laporan keuangan secara lengkap selama tahun } 2014 \\
\text { sampai dengan } 2016\end{array}$ & (9) & $(27)$ \\
\hline $\begin{array}{l}\text { Perusahaan manufaktur yang tidak menyampaikan } \\
\text { laporan keuangan dalam mata uang rupiah selama } \\
\text { periode } 2014 \text { sampai dengan } 2016\end{array}$ & (34) & (102) \\
\hline $\begin{array}{l}\text { Perusahaan manufaktur yang laporan keuangannya tidak } \\
\text { berakhir pada tanggal } 31 \text { Desember pada tahun } 2014 \\
\text { sampai dengan } 2016\end{array}$ & (3) & (9) \\
\hline $\begin{array}{l}\text { Perusahaan manufaktur yang tidak memperoleh laba } \\
\text { selama periode } 2014 \text { sampai dengan } 2016\end{array}$ & (43) & (129) \\
\hline Jumlah sampel penelitian & 60 & 180 \\
\hline
\end{tabular}

Sumber: Data yang diperoleh dan diolah 
Pengukuran yang akan dilakukan terhadap corporate social responsibility disclosure dalam penelitian ini adalah dengan cara memberikan sebuah checklist terhadap item-item pengungkapan yang telah dtentukan. Apabila item pengungkapan tersebut terdapat dalam laporan tahunan perusahaan maka diberikan nilai 1 dan jika item tidak ada dalam laporan tahunan perusahaan maka akan diberikan nilai 0 (Isa dan Muhammad 2015) dan dapat dihitung dengan rumus:

$$
R S=\sum_{i=1}^{n} d i
$$

Keterangan:

RS = Reporting Score

di $=1$ jika butir indeks diungkapkan dan 0 jika

butir indeks tidak diungkapkan.

$\mathrm{n}$ = jumlah butir yang seharusnya

diungkapkan.

$\mathrm{i}=1,2,3$.

Managerial ownership (kepemilikan saham oleh manajerial) akan diukur dengan persentase jumlah saham yang dimiliki oleh pihak manajerial perusahaan dari keseluruhan saham perusahaan yang telah diterbitkan (Khan et al. 2013).

Public ownership (kepemilikan saham oleh publik) akan diukur dengan persentase jumlah saham yang dimiliki oleh pihak publik dari keseluruhan saham perusahaan yang telah diterbitkan (Khan et al. 2013).

Kehadiran komisaris independen di dewan komisaris dianggap sebagai mekanisme corporate governance yang utama. Secara umum diyakini bahwa direksi luar yang independen akan memperkuat dewan dengan memantau kegiatan manajemen, dan memastikan bahwa kepentingan investor dilindungi (Khan et al. 2013).

Komite Audit adalah sekelompok orang yang dibentuk untuk membantu dewan komisaris (Fatimah 2015). Komite audit diukur berdasarkan persentase jumlah komite audit yang berasal dari komisaris independen dari seluruh jumlah anggota komite audit. Ukuran dewan adalah jumlah personel dewan direksi dan komisaris dalam suatu perusahaan.

Penelitian ini menggunakan metode analisis berganda dengan persamaan sebagai berikut:

$$
\begin{aligned}
\text { CSRD }=\beta_{0}+ & \beta_{1} \text { MOWN }_{i t}+\beta_{2} \text { PUB }_{i t} \\
& +\beta_{3} \text { BIND }_{i t} \\
& +\beta_{4} \text { AUDICOM }_{i t}+\beta_{5} B S_{i t} \\
& +\varepsilon_{i t}
\end{aligned}
$$

\begin{tabular}{|c|c|}
\hline CSRD & $\begin{aligned}= & \text { Corporate Social } \\
& \text { Responsibility Disclosure }\end{aligned}$ \\
\hline MOWN $=K$ & milikan Menejerial \\
\hline PUB & $=$ Kepemilikan Publik \\
\hline ND & = Dewan Direksi Independen \\
\hline JDICOM & $=$ Komite Audit \\
\hline & $=$ Ukuran Dewan \\
\hline
\end{tabular}

Keterangan:

\section{HASIL PENELITIAN}

Hasil pengolahan statistic deskriptif variablevariabel yang digunakan dapat dilihat pada tabel di bawah ini: 
Tabel 2 Hasil Uji Statistik Deskriptif

\begin{tabular}{lcrrrr}
\hline Variabel & N & \multicolumn{1}{c}{ Mean } & \multicolumn{1}{c}{ Std. Deviation } & Maximum & Minimum \\
\hline CSRD & 180 & 0.25690883 & 0.126854105 & 0.6025641 & 0.025641026 \\
MOWN & 180 & 0.01802685 & 0.056204586 & 0.3732242 & 0.000000000 \\
PUB & 180 & 0.27883521 & 0.150729548 & 0.6706821 & 0.001446769 \\
BIND & 180 & 0.69074473 & 0.049470588 & 0.66666666 & 0.100000000 \\
AUDICOM & 180 & 3,1166667 & 0.41312273 & 5 & 2 \\
BS & 180 & 5.33 & 2.581 & 16 & 2 \\
\hline
\end{tabular}

Sumber: Hasil pengolahan data SPSS

Tabel 3 Hasil Uji t

\begin{tabular}{lcc}
\hline \multicolumn{1}{c}{ Variabel } & B & Sig. \\
\hline Konstanta & 0.011 & 0.883 \\
Kepemilikan Managerial & 0.171 & 0.274 \\
Kepemilikan Publik & 0.154 & 0.009 \\
Dewan Direksi Independen & 0.049 & 0.493 \\
Komite Audit & 0.009 & 0.694 \\
Ukuran Dewan & 0.020 & 0.000 \\
\hline
\end{tabular}

Sumber: Hasil pengolahan data SPS.

Hasil uji t untuk Kepemilikan Managerial menunjukkan nilai koefisien sebesar 0.171 dan sig. sebesar 0.274 lebih besar daripada 0.05 yang artinya $\mathrm{H}_{1}$ tidak dapat diterima Artinya Kepemilikan Managerial tidak berpengaruh terhadap corporate social responsibility disclosure. Dengan adanya saham yang dimiliki oleh management hal tersebut tidak mempengaruhin perusahaan dalam melakukan corporate social responsibility disclosure. Dengan kata lain, manajemen perusahaan mungkin tidak berinvestasi dalam kegiatan yang bertanggung jawab secara sosial karena biaya investasi dalam kegiatan ini mungkin jauh lebih besar daripada manfaat potensinya dalam mengungkapkan corporate social responsibility perusahaan (Khan et al. 2013).

Hasil uji $t$ untuk Kepemilikan Publik menunjukkan nilai koefisien sebesar 0.154 dan sig. sebesar 0.009 lebih kecil daripada 0.05 yang artinya $\mathrm{H}_{2}$ dapat diterima. Artinya Kepemilkan Publik berpengaruh terhadap corporate social responsibility disclosure. Dengan adanya kepemilikan saham oleh publik mempengaruhi perusahaan dalam melakukan pengungkapan corporate social responsibility disclosure. Artinya semakin banyak jumlah kepemilikan saham publik, maka semakin tinggi tingkat pengungkapan corporate social responsibility perusahaan.

Hasil uji $t$ untuk Dewan Direksi Independen menunjukan nilai koefisien 0.049 dan sig. sebesar 0.493 yang lebih besar daripada 0.05 yang artinya $\mathrm{H}_{4}$ tidak dapat diterima. Hal ini menunjukan banyaknya dewan direksi independen tidak mempengaruhi perusahaan dalam melakukan kegiatan corporate social responsibility dislosure. Proporsi direksi independen dalam dewan direksi pada perusahaan sampel masih rendah, sehingga kemampuan direksi independen dalam memantau perilaku dewan direksi (manajemen) dan memberikan pengaruh dalam pengungkapan corporate social responsibility 
belum maksimal (Susanto \& Joshua 2018, Allegrini \& Greco 2013).

Hasil uji $t$ untuk Komite Audit menunjukkan nilai koefisien sebesar 0.009 dan sig. sebesar 0.694 lebih besar daripada 0.05 yang artinya $\mathrm{H}_{5}$ tidak dapat diterima. Dengan adanya komite audit dalam sebuah perusahaan tidak mempengaruhi perusahaan dalam melakukan kegiatan corporate social responsibility disclosure. Komposisi Komite Audit memiliki efek negatif pada pengungkapan tanggung jawab sosial perusahaan dari perusahaan yang dijadikan sampel. Oleh karena itu, disimpulkan bahwa, bukan komposisi komite audit yang penting tetapi mungkin keahlian anggota dan kehadiran rutin mereka untuk rapat mungkin sangat penting bagi kinerja keuangan perusahaan dan dengan perluasan kemampuan mereka untuk melakukan kegiatan CSR dan pengungkapan terkait.

Hasil uji $t$ untuk Ukuran Dewan menunjukkan nilai koefisien sebesar 0.020 dan sig. sebesar 0.000 lebih kecil daripada 0.05 yang artinya $\mathrm{H}_{6}$ dapat diterima. Artinya Ukuran Dewan berpengaruh terhadap corporate social responsibility disclosure. Dengan adanya Ukuran Dewan, besarnya jajaran dewan dalam suatu perusahaan tidak mempengaruhi perusahaan dalam melakukan pengungkapan corporate social responsibility disclosure. Dengan kewenangan yang dimiliki dewan komisaris, maka dewan komisaris memiliki kekuatan untuk memberikan tekanan dan mempengaruhin manejemen dalam melakukan pengungkapan corporate social responsibility, sehingga semakin besar ukuran dewan maka kemungkinan besar melakukan pengungkapan corporate social responsibility lebih banyak (Wagiu dan Mekel 2014).

\section{PENUTUP}

Berdasarkan hasil uji di atas, dapat disimpulkan bahwa kepemilikan menegerial, dewan direksi independen, komite audit tidak mempengaruhi pengungkapan tanggung jawab sosial perusahaan manufaktur di Indonesia sedangkan variabel lain yang diteliti dalam penelitian ini, yaitu kepemilikan publik, dan ukuran dewan mempengaruhi pengungkapan tanggung jawab sosial perusahaan. Dengan tingginya kepemilikan publik dan ukuran dewan yang memadai diharapkan para pemangku kepentingan dapat lebih memperhatikan laporan tanggung jawab sosial perusahaan agar pengungkapan tanggung jawab sosial perusahaan akan semakin baik. Adanya kepemilikan oleh menegerial, adanya dewan direksi independen dan komite audit dalam perusahaan rupanya tidak dapat menjamin bahwa suatu perusahaan akan melakukan pengungkapan tanggung jawab social perusahaan. Karena itu, perusahaan publik di Indonesia diharapkan memiliki kepemilikan menegerial, dewan direksi independen, dan komite audit distruktur organisasinya agar lebih menunjang dalam melakukan proses pengungkapan tanggung jawab social perusahaan tersebut.

Penelitian ini juga menunjukkan bahwa pengungkapan tanggung jawab sosial perusahaan manufaktur di Indonesia masih minim namun telah mengalami kenaikan dalam tiga tahun terakhir (2014-2016). Diharapkan agar perusahaan di Indonesia memiliki laporan tanggung jawab sosial yang lebih baik lagi.

Penelitian ini memiliki batasan tahun dan objek penelitian. Penelitian selanjutnya diharapkan dapat mengganti tahun penelitian dan objek penelitian untuk mendukung hasil penelitian ini. Selain itu, peneliti selanjutnya dapat menggunakan pengukuran lain untuk melihat dampak keberagaman dari kepemilikan menegerial, kepemilikan publik, dewan direksi independen, komite audit dan ukuran dewan terhadap pengungkapan tanggung jawab sosial perusahaan. 


\section{REFERENCES:}

Allegrini, M. and Greco, G. 2013. Corporate boards, audit committees and voluntary disclosure: evidence from Italian Listed Companies, Journal of Management \& Governance, 17(1), 187-216.

Barako, D. G., \& Brown, A. M. 2008. Corporate Social Reporting and Board Representation: Evidence from the Kenyan Banking Sector. Journal of Management and Governance, 12(4), 309-324.

Belkaoui, A. 2006. Accounting Theory. Fifth Edition. Thomson Learning, Singapore. Diterjemahkan oleh Ali Akbar Yulianto: Teori Akuntansi. Buku Satu, Edisi Kelima. Salemba Empat, Jakarta.

Dewanta, D. 2011. Pengaruh Mekanisme Corporate Governance terhadap Pengungkapan Tanggung Jawab Sosial pada Perusahaan ILQ 45 yang terdaftar di Bursa Efek Indonesia. E-Journal, 9(4)

Fatimah, Siti, Makhdalena, Trisnawati. 2015. Pengaruh Komisaris Independen dan Komite Audit Terhadap Pengaruh CSR Perusahaan Pertambangan di Bursa Efek Indonesia Periode 2012 s.d 2014. Jurnal Akuntansi, 4(8).

Haniffa, R. M., \& Cooke, T. E. 2005. The Impact of Culture and Governance on Corporate Reporting. Journal of Accounting and Public Policy, 24(5), 391-430.

Isa, Muhammad Aminu dan Sabo Muhammad. 2015. The Impact of Board Characteristics on Corporate Social Responsibility Disclosure: Evidence from Nigerian Food Product Firm. International Journal of Management Science and Business Administration, 1(12), 34-45.

IJensen \& Meckling, 1976. The Theory of the Firm: Manajerial Behaviour, Agency Cost, and Ownership Structure, Journal of Financial and Economics, 4, 305-360

Jo, H., \& Harjoto, M. A. 2011. Corporate governance and firm value: The impact of corporate social responsibility. Journal of Business Ethics, Vol.103, No.3, 351-383.

Khan, A., Muttakin, M. B., \& Siddiqui, J. 2013. Corporate governance and corporate social responsibility disclosures: Evidence from an emerging economy. Journal of business ethics, Vol.114 No.2, 207-223.

Lipton, M. \& Lorsch, J. W. 1992, 'A Modest Proposal for Improved Corporate Governance, E-Journal. Business Lawyer, Vol.48, No.1 59-77.

Sembiring, E.D. 2005. Karakteristik Perusahaan dan Pengungkapan Tanggung Jawab Sosial: Studi Empiris Pada Perusahaan Yang Tercatat Di Bursa Efek Jakarta. SNA VII Solo

Sriayu, Gusti Ayu Putu Wiwik dan Nimba, Ni Putu Sri Harta. 2013. Pengaruh Karakteristik Perusahaan Terhadap Corporate Social Responsibility Disclosure. E-Jurnal Akuntansi Universitas Udayana, 5(2), 326 $-344$.

Susanto, Y.K. \& Joshua, D. 2018. Pengaruh tata kelola perusahaan dan Karakteristik Perusahaan Terhadap Pengungkapan Tanggung Jawab Sosial Perusahaan. EKUITAS (Jurnal Ekonomi dan Keuangan), 2(4), 572-590.

Susanto, Y.K. 2019. Corporate Social Responsibility Disclosure: Corporate Governance and Profitability. South East Asia Journal of Contemporary Business, Economics and Law, 20(1), 39-44.

Turley, S., and M. Zaman. 2004. The corporate govemance effects of audit committees. Joumal of Management and Govenance, 8(3), 305-32.

Wagiu, Frily Ansyelia dan Peggy A Mekel .2014. The Effect of Firm Size,Profitability, Leverage and Board Size on Disclosure of Corporate Social Responsibility in Company's Annual Reports. Jurnal EMBA, 2(3), 15401549. 